\title{
SPATIOTEMPORAL DYNAMICS AND INFLUENCING FACTORS OF SOIL EROSION IN THE DIANCHI LAKE BASIN, CHINA
}

\author{
PENG, S. Y. ${ }^{*}-$ ZHAO, Z. X. \\ School of Tourism and Geography, Yunnan Normal University, Kunming 650500, China \\ *Corresponding author \\ e-mail:frankmei@126.com
}

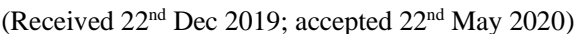

\begin{abstract}
Mastering the spatiotemporal evolution tendency of soil erosion and its influencing factors is of great significance for optimizing regional soil and water conservation measures, ensuring sustainable development. This study calculated the soil erosion modulus and investigated the spatiotemporal dynamics of soil erosion intensity in the Dianchi Lake basin of China during the 1999-2014 period based on the revised universal soil loss equation (RUSLE) model and geographic information system (GIS) and remote sensing (RS) techniques. The results showed that the soil erosion in the Dianchi Lake basin has been improved in the past fifteen years, and the erosion area is shrinking continuously, but the unit erosion intensity is increasing, indicating that local area erosion is still serious. The analysis results show that soil erosion can easily occur of cultivated lands with slopes of $8-25^{\circ}$ and a vegetation coverage in $0 \%-45 \%$ forestland. The area of intensity of soil erosion exhibited a decreasing trend, indicating a gradual improvement in the situation of soil erosion. However, the soil erosion phenomenon in cultivated land, forest land and bare land with a slope of $8-25^{\circ}$ and a vegetation coverage of $45 \%$ or less is severely. This study provides a theoretical foundation and methodological reference for research on soil erosion and its influencing factors in similar highlands Lake basin.
\end{abstract}

Keywords: soil erosion, RUSLE, geographic information system, spatial relationship, erosion factor, highland lakes

\section{Introduction}

Soil erosion is a global environmental problem, which can cause issues such as land degradation, declines in soil fertility and quality, and deterioration of the ecological environment (Montgomeryet al., 2007; Lal, 2003). During soil erosion, large amounts of slope sediment are scoured, transported, and deposited into rivers and lakes, resulting in sedimentation of these water bodies, weakening the flood discharge capacity of riverbeds and increasing the risk of flood disasters (Gao and Cao, 2011). Additionally, large amounts of soil nutrients such as nitrogen, phosphorus, and potassium are lost, resulting in land infertility, water eutrophication, and ecological imbalances, severely restricting the sustainable development of society, the economy, and environment (Hartanto et al., 2003; Pimentel et al., 1995). China has vast amounts of land and yet suffers from relatively severe soil erosion. According to the second national remote sensing survey of soil erosion, soil and water loss comprised $37.42 \%$ of China's total land area. In this scenario, the economic loss caused by soil and water loss can no longer be understated.

The traditional method of soil erosion survey is time-consuming and long-term, and it is almost impossible to determine the amount of soil erosion in the medium-scale basin. The Universal Soil Loss Equation (USLE) has been widely used in soil erosion related research because of its simple calculation method, low data volume and versatile results. The model is an empirical model which is derived from the inductive statistics of soil erosion and runoff observations from the US Department of Agriculture (USDA) 
using more than 10,000 runoff plots (Wischmerie and Smith, 1965). However, due to the limitations of the USLE model, the US Department of Agriculture organized scientists to improve the model in 1985, and in 1992 a revised version of the Universal Soil Loss Equation (RUSLE) was issued (Fu et al., 2011; Kinnellet al., 2010). The RUSLE model involves a wide range of areas, considers multiple natural influence factors, and has a simple form and a straightforward calculation method (Angima et al., 2003). Therefore, the model has strong practicability and has been widely used in soil erosion evaluation by scholars, institutions and government departments at home and abroad. Since the 1980s, with the rapid development of spatial information technology, RS and GIS have been widely used in soil erosion assessment (Peng et al., 2018). RS is mainly used for the collection and extraction of soil erosion information. GIS is mainly used for the management and analysis of erosion data and the calculation of impact factors. The integration of RUSLE model with GIS and RS technology can quantitatively analyze the spatial and temporal changes of soil erosion in the basin and the relationship between soil erosion and impact factors (Zhu et al., 2015). Alexakiset al. (2013), Xin et al. (2009), Zha et al. (2015), Lin et al. (2011) evaluated the evolutionary trend of the temporal and spatial patterns of erosion areas by integrating of the RUSLE model with GIS. Slope, land use type, vegetation coverage and soil erodibility factors are important factors affecting soil erosion. Therefore, it is necessary to explore their relationship with soil erosion. Vijithet al. (2012), Kinnell et al. (2014, 2018) and $\mathrm{Hu}$ et al. (2018) compared the differences in soil erosion on different slopes based on soil erosion models. The study of land use and soil erosion focuses on the extent to which land cover types and their effects have an impact on soil erosion intensity (Li et al., 2014; Manojlovic et al., 2017; Mondal et al., 2015; Xiao et al., 2015; Zokaib and Naser, 2011). The increase in vegetation coverage can effectively slow down the occurrence of soil erosion. The research in this area mainly focuses on the relationship between the change of coverage and erosion, and the study of erosion under different coverage conditions of different rainfall (Jian et al., 2016; Yan et al., 2013; Yao et al., 2018; Zhou et al., 2006). Soil erodibility is an important indicator for assessing soil sensitivity to erosion and an important parameter for soil erosion prediction. Since this factor is closely related to the physical and chemical properties of the soil and the rainfall erosion intensity, many studies have focused on the determination of soil erodibility values under different rainfall conditions in different regions (Panagos et al., 2012; Saygin et al., 2017; Wang et al., 2013).

The Dianchi Lake basin is the most densely populated area in Yunnan Province of China, characterized by a high level of human activities and economic development. In recent years, rapid development and urbanization have resulted in the continuous deterioration of water quality in the Dianchi Lake basin, where soil erosion has emerged as a primary source of pollution. It is necessary to analyze the soil erosion trend in the lake basin from the perspective of spatial variation, and identify the significance of the effects of various factors on soil erosion. Such work can provide decision-making support for pollution prevention and control measures as well as sustainable urban development in the Dianchi Lake basin area.

Based on the above reasons, RUSLE model was selected and used in this study by integrating with GIS and RS to analyse the spatial variation of soil erosion and its influencing factors in the Dianchi Lake basin, China, over the 1999-2014 period. The objectives of this present were: (1) to reveal the spatiotemporal changes of soil erosion; (2) to find major influencing factors on soil erosion in the study area. 


\section{Materials and methods}

\section{Study sites}

The Dianchi Lake basin is located in the middle of the Yunnan, China (Fig. 1). It is located in the watershed of the Yangtze River, the Pearl River and the Honghe River. The geographical coordinates are $24^{\circ} 28^{\prime}-25^{\circ} 28^{\prime} \mathrm{N}, 102^{\circ} 30^{\prime}-103^{\circ} 00^{\prime} \mathrm{E}$. The drainage area is $2,920 \mathrm{~km}^{2}$, the hilly area is relatively large, accounting for $69.5 \%$ of the total area; the plains and basins account for $20.2 \%$ of the total area; the Dianchi Lake water body accounts for $10.3 \%$.

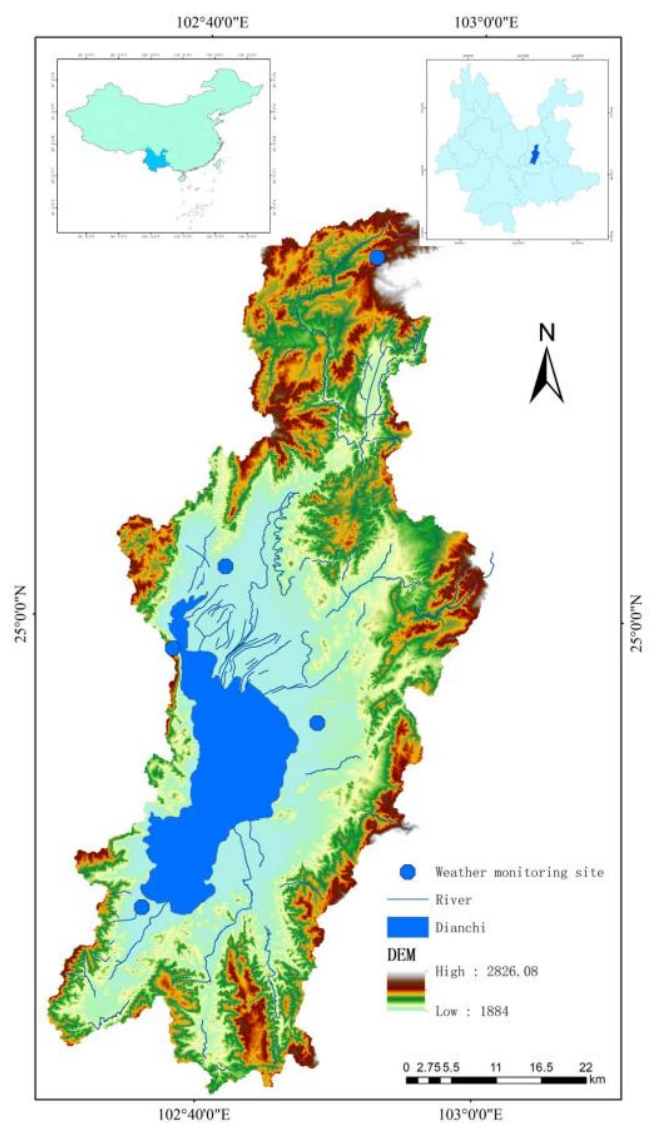

Figure 1. Location of Dianchi basin, Yunnan, China

\section{Data source}

The data used in this study include: (1) Daily rainfall data of five monitoring points (Kunming Station, Taihuashan Station, Jinning Station, Yuming Station, Chenggong Station) in Dianchi basin in 1999, 2005 and 2014; (2) Remote sensing image data includes: LandsatTM images on December 25, 1999, March 01, 2005, and November 25, 2014; (3) Digital elevation model (DEM) data in Dianchi basin with spatial resolution of $30 \mathrm{~m}$; (4) Soil data, Dianchi basin 1:25 Million soil type data.

\section{Soil erosion model}

The RUSLE comprehensively reflects the effects of natural factors and human activities on soil erosion using five factors, namely rainfall erosivity factor, soil 
erodibility factor, topographic factor, vegetation cover factor, and soil and water conservation practice factor. Among the factors, rainfall erosivity is a dynamic factor of soil erosion. The soil erodibility factor reflects the difficulty level of soil erosion caused by rainfall (Wang et al., 2018; Wen et al., 2013). Topographic factors affect the formation and development of surface vegetation thus controlling the movement state and direction of surface runoff (Wang et al., 2018). The vegetation cover factor as well as the soil and water conservation practice factor affect the distribution of surface vegetation and the level of human activities, thereby directly or indirectly affecting the occurrence and development of soil erosion (Miao et al., 2012). This model is expressed as follows:

$$
A=R^{*} K^{*} L S^{*} C^{*} P
$$

where $A$ is the annual average erosion modulus $\left(\mathrm{t} \cdot \mathrm{hm}^{-2} \cdot \mathrm{a}^{-1}\right) ; R$ is the rainfall erosivity factor $\left(\mathrm{MJ} \cdot \mathrm{mm} \cdot \mathrm{hm}^{-2} \cdot \mathrm{h}^{-1} \cdot \mathrm{a}^{-1}\right) ; K$ is the soil erodibility factor $\left(\mathrm{t} \cdot \mathrm{hm}^{2} \cdot \mathrm{h} \cdot \mathrm{hm}^{-2} \cdot \mathrm{MJ}^{-1} \cdot \mathrm{mm}^{-1}\right) ; L$ is the slope length factor; $S$ is the slope steepness factor; $C$ is the vegetation coverage and management factor; $P$ is the soil and water conservation measure factor. Among them, $L, S, C$, and $P$ are all dimensionless.

\section{Rainfall erosivity factor}

The rainfall erosivity factor $\mathrm{R}$ refers to the potential ability of rainfall to cause soil erosion and is related to the intensity, duration, raindrop size, raindrop velocity, and amount of rainfall (Nyssen et al., 2005). Zhang et al. compared the results of rainfall erosivity from different types of representative rainfall data, indicating that the calculation of mean annual erosivity based on daily rainfall yielded the highest accuracy (Zhang and Jin, 2003). In the present study, the rainfall erosivity model was constructed based on daily rainfall data using the following equation:

$$
\begin{gathered}
M_{i}=\alpha \sum_{j=1}^{k}\left(D_{j}\right)^{\beta} \\
\beta=0.8363+\frac{18.144}{P_{d 12}}+\frac{24.455}{p_{y 12}} \\
\alpha=21.586 \beta^{-7.1891}
\end{gathered}
$$

In Equation 2, $M_{i}$ is rainfall erosivity in the $i$-th half month $\left(\mathrm{MJ} \cdot \mathrm{mm} \cdot \mathrm{hm}^{-2} \cdot \mathrm{h}^{-1} \cdot \mathrm{a}^{-1}\right)$, $K$ is the number of days in the $i$-th half month, $D_{j}$ is the erosive daily rainfall on the $j$ th day in the $i$-th half month (daily rainfall $\geqq 12 \mathrm{~mm}$; otherwise $D_{j}=0$ ), and $\alpha$ and $\beta$ are two model parameters to be determined by Equation 2. In Equation3, $P_{d 12}$ and $P_{y 12}$ are the daily and yearly averages of $\geqq 12 \mathrm{~mm}$ daily rainfall, respectively. According to these equations, daily rainfall erosivity data at monitoring points in the Dianchi Lake basin were calculated for three study years, using the 1999, 2005, and 2014 data from five weather stations in the lake basin. The spatial distribution of rainfall erosivity across the lake basin was then calculated by spatial interpolation using the ArcGIS tool (Fig. 2). 

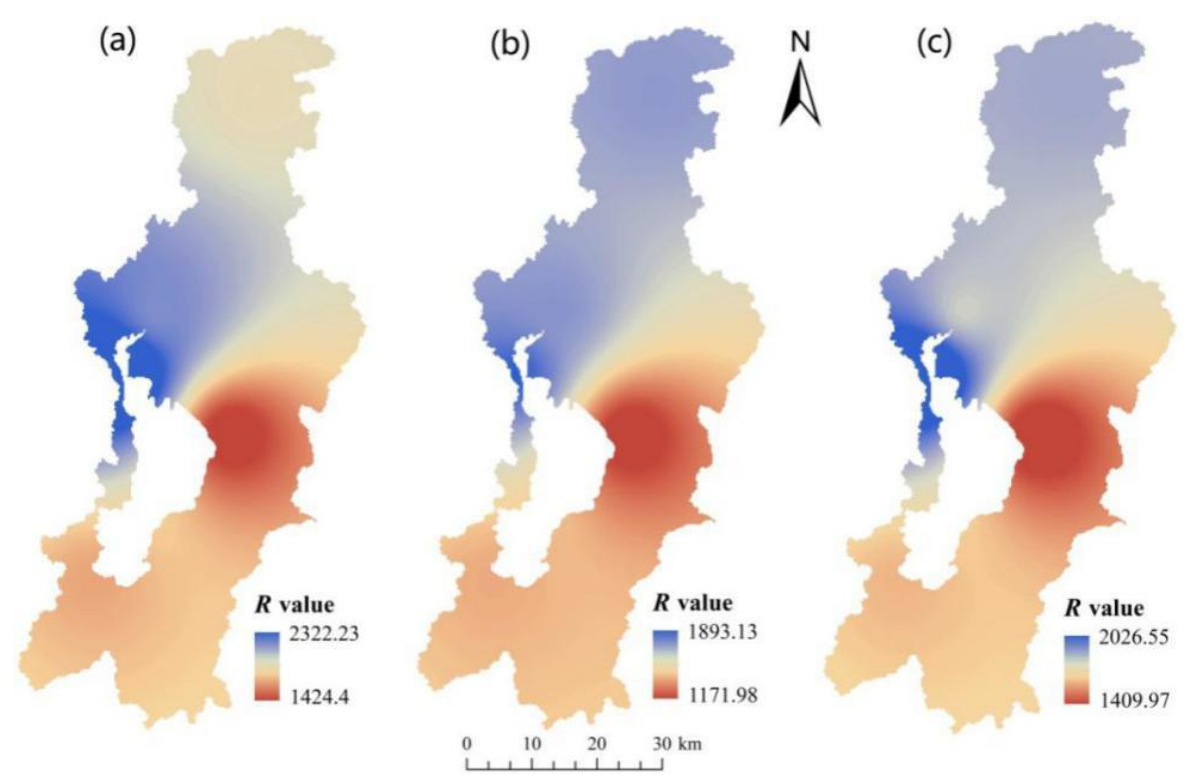

Figure 2. Rainfall erosivity distribution map of Dianchi Lake basin. (a) 1999, (b) 2005 and (c) 2014

\section{Soil erodibility factor}

In the present study, the soil erodibility factor $\mathrm{K}$ was calculated using the erosion productivity impact calculator (EPIC) of Wischmeier and Smith (1971), which is expressed as follows:

$$
\begin{aligned}
& K_{E P I C}=0.1317\left\{0.2+0.3 \exp \left[-0.0256 S A D\left(1-\frac{S I L}{100}\right)\right]\right\} \\
& {\left[\frac{S I L}{C L A+S I L}\right]^{0.3}\left\{1.0-\frac{0.25 C}{C+\exp (3.72-2.95 C)}\right\}} \\
& \left\{1.0-\frac{0.7(1-S A D / 100)}{(1-S A D / 100)+\exp (-5.51+22.9(1-S A D / 100))}\right\}
\end{aligned}
$$

where $S A D$, SIL, CLA, and $C$ are the sand, silt, clay, and organic carbon contents, respectively (unit: \%). The $\mathrm{K}$ values in the Dianchi Lake basin were calculated by querying the "Records of Yunnan Soil Species" in combination with the soil distribution map of Yunnan Province. The spatial distribution map of the K values was obtained using the ArcGIS (Fig. 3a).

\section{Slope length and steepness factor}

The slope length factor $\mathrm{L}$ and slope steepness factor $\mathrm{S}$ affect the formation and erosion level of surface runoff, reflect the topographic features, and play a relatively important role in soil erosion among topographic indicators. Thus, the slope length and steepness factor (LS) is an external factor that must be considered for soil erosion as it determines the accuracy and reliability of the soil erosion study. In this study, the LS factor was calculated using the equation proposed by Liu et al. (2000). The slope length factor $\mathrm{L}$ is calculated as follows: 


$$
L=(h / 22.13)^{m}
$$

where $L$ is the slope length factor, $h$ is the slope length value, and $m$ is the slope length index. The value of $\mathrm{m}$ is as follows:

$$
\mathrm{m}=\left\{\begin{array}{cc}
0.5 & \theta>5^{\circ} \\
0.4 & 3^{\circ}<\theta \leq 5^{\circ} \\
0.3 & 1^{\circ}<\theta \leq 3^{\circ} \\
0.2 & \theta \leq 1^{\circ}
\end{array}\right.
$$

where $\theta$ is the slope value.

The $S$ factor is the ratio of soil loss per unit area at any slope to that at the slope of a standard plot, provided all other conditions are identical. Slope is a relatively stable parameter. In this study, the slope steepness factor algorithm of McCool for gentle slopes was combined with the slope steepness factor equation of Liu et al. (Liu et al., 2000; Mccool et al., 1987). for steep slopes to calculate the $S$ factor as follows:

$$
\left\{\begin{array}{cc}
10.8 \sin \theta+0.03 & \theta<5^{\circ} \\
16.8 \sin \theta-0.5 & 5^{\circ} \leq \theta<10^{\circ} \\
21.9 \sin \theta-0.96 & \theta \geq 10^{\circ}
\end{array}\right.
$$

The spatial distribution map of the LS factor (Fig. 3b) was obtained based on calculations using a combination of Equations 6-8.

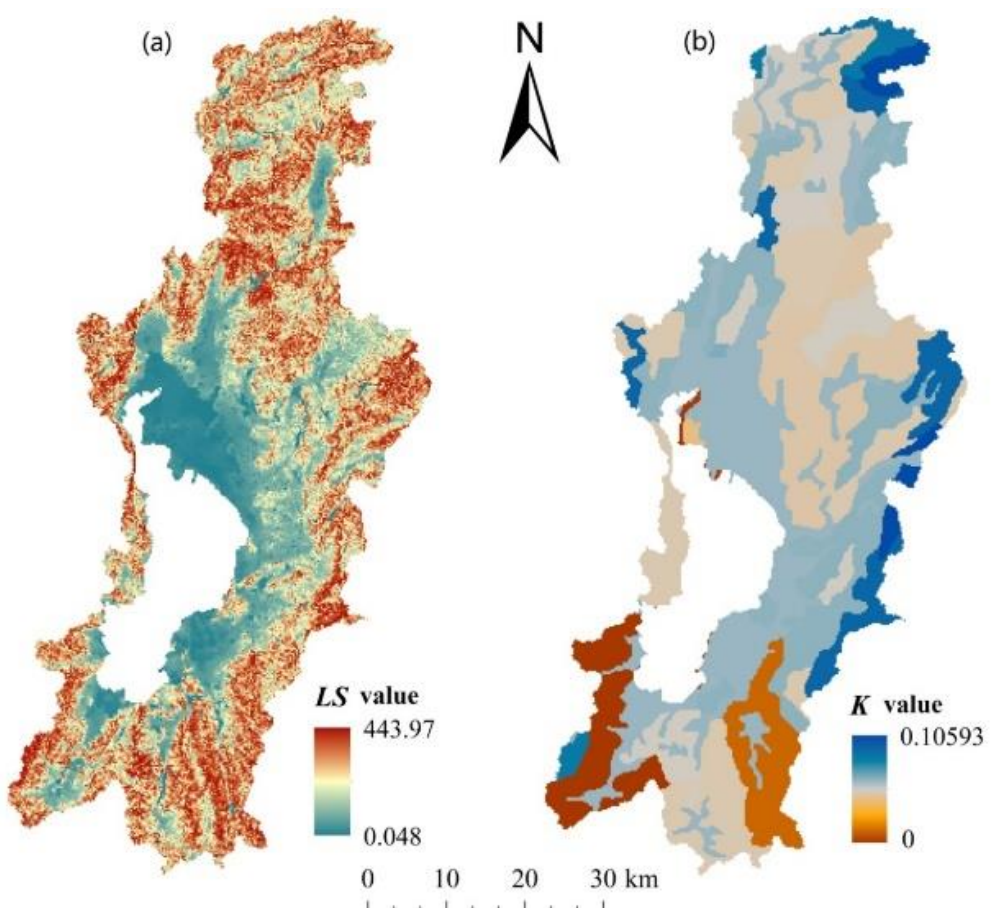

Figure 3. The distribution of slope length factor $(L S)$ and soil erodibility factor $(K)$ in Dianchi Lake basin. (a) LS and (b) $K$ 


\section{Vegetation cover and management factor}

In this study, the $\mathrm{C}$ factor in the Dianchi Lake basin was estimated using the calculation model established by Cai et al. (Chong, 2000):

$$
\left\{\begin{array}{ccrl}
C & =1 & c & <0 \\
C=0.6508-0.3436 \lg c & 0<c & <78.3 \% \\
C & =0 & c & >78.3 \%
\end{array}\right.
$$

where $C$ is the vegetation cover and management factor and $\mathrm{c}$ is the vegetation coverage. First, the $\mathrm{c}$ value was extracted using remote sensing images. Then, the spatial distribution map of the $C$ value (Fig. 4) was obtained through calculation using the ArcGIS software according to Equation 9.
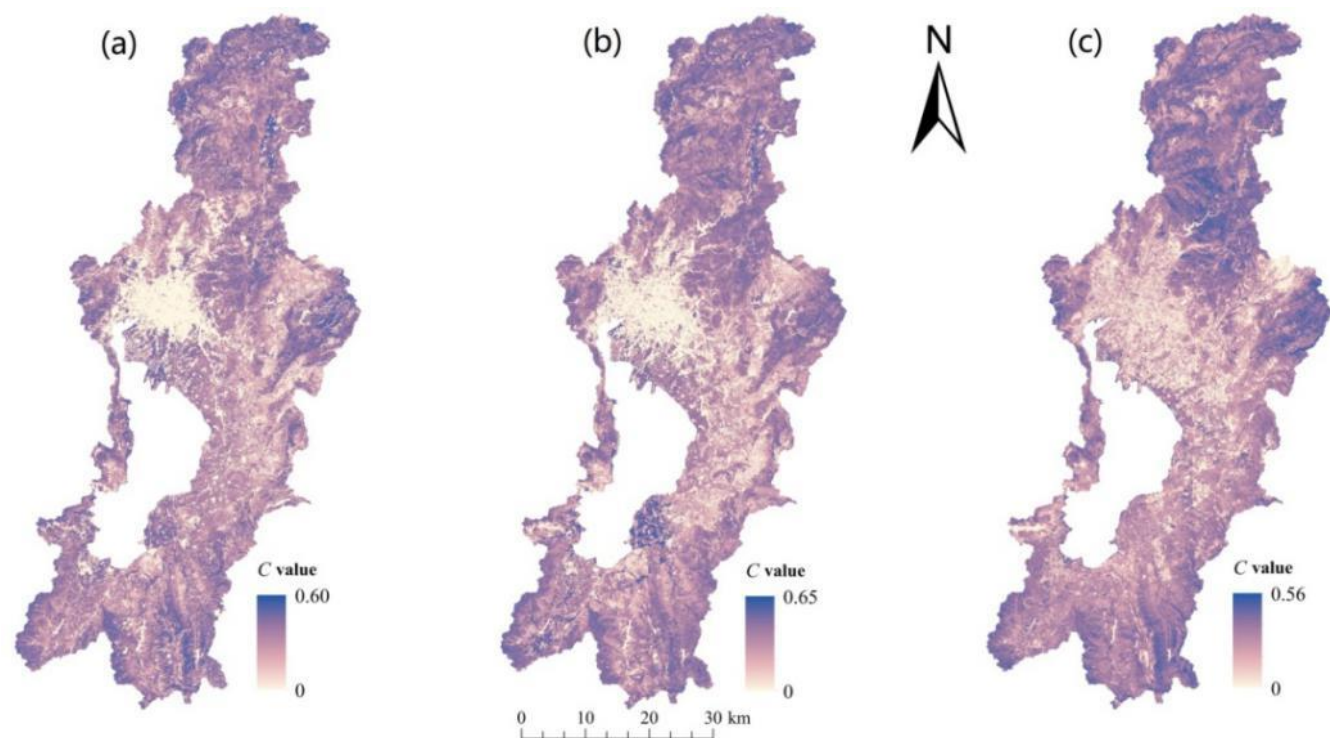

Figure 4. The distribution of vegetation coverage and management factors $(C)$ in Dianchi Lake basin. (a) 1999, (b) 2005 and (c) 2014

\section{Soil and water conservation practice factor}

The soil and water conservation practice factor $\mathrm{P}$ is the proportion of the soil loss under specific practice in the corresponding soil loss under no conservation practice, ranging between 0 and 1 (Renard et al., 1997). $P$ value of 0 indicates that soil and water conservation practices are well implemented in a region where erosion is unlikely to occur. $\mathrm{P}$ value of 1 indicates no implementation of any soil and water conservation practices. The conservation practices are generally of cultivation and engineering types. Common conservation practices include strip tillage and contour tillage, whereas engineering practices include building terraces, establishing drainage practices, and returning cropland to forests. According to existing studies, the $\mathrm{P}$ value was determined in the present study based on the land use situation and the soil and water conservation practices implemented in the lake basin area (Zhao et al., 2007). Specifically, the $\mathrm{P}$ value in the lake basin was obtained using a combination of land use/cover types and soil and water conservation practices implemented in the Dianchi Lake basin (Table 1). 
Table 1. The P value of soil and water conservation measures factor in Dianchi basin

\begin{tabular}{c|c|c|c|c|c|c}
\hline Land use/land cover & Water & Cropland & Forest land & Bare land & Construction land & Grass land \\
\hline P value & 0 & 0.59 & 1.0 & 1.0 & 0 & 1.0 \\
\hline
\end{tabular}

\section{Results}

\section{Spatial distribution of the influence factors}

As can be seen from Figure 2, significant consistency can be witnessed in the spatial distribution of rainfall erosivity factor $(\mathrm{R})$ during the studied period. The areas with the strongest and weakest rainfall erosions are located on the northwestern and eastern shores of Dianchi Lake, respectively. On the whole, rainfall erosion in the north of the basin is remarkably stronger than that in the south. According to Figure $3 a$, the slope length and steepness factor (LS) is distributed in a pattern that is low in the center and high in the surroundings. And in Figure 3b, the area with the largest soil erodibility factor $(\mathrm{K})$ is located in the north and eastern edge of the basin; and the area with the lowest value is basically located in the south of the basin. Besides, the vegetation cover and management factor (C) is fluctuated between 0 and 0.65 (as shown in Fig. 4). The area with high values is mainly located at the higher elevation at the northern and southern ends of the basin, while the area with low values is at the main urban area of Kunming in the middle of the basin. And the scope of the low-value area has been continuously extended due to the massive increase in the impermeable surface with the acceleration of urbanization from 1999 to 2014.

\section{Classification of soil erosion in the basin}

The above-mentioned maps were subjected to overlay analysis using the ArcGIS grid calculator to obtain the soil erosion modulus in the study area for the three years of 1999, 2005, and 2014. The soil erosion intensity map of the lake basin (Fig. 5) was generated based on classification following the "Standard for Classification and Grading of Soil Erosion (SL90-2007)" enacted in 2007 by the Ministry of Water Resources of China.

Figure 5 shows that in all three stages, most of the study area is yellow with a small erosion modulus between 0 and $500 \mathrm{t} /\left(\mathrm{km}^{2} \cdot \mathrm{a}\right)$, which belongs to a tiny erosion area according to the erosion standard enacted by the Ministry of Water Resources of China. Green areas representing an erosion modulus of $500-2,500 \mathrm{t} /\left(\mathrm{km}^{2} \cdot \mathrm{a}\right)$ and purple representing an erosion modulus of 2,500-5,000 $\mathrm{t} /\left(\mathrm{km}^{2} \cdot \mathrm{a}\right)$ were prevalent in the remaining parts of the study area, denoting slight and moderate erosion areas, respectively. Only a small proportion of the study area is depicted in red, indicating severe erosion. With regard to spatial distribution, tiny erosion areas were primarily distributed in the main city district of Kunming in the northern basin and Jinning County in the southern basin. Slight and moderate erosion classes exhibited a staggered distribution in the northern, southern, and eastern basins, being especially concentrated in the northernmost and southernmost parts. Severe erosion was sporadically distributed in a very small proportion of the lake basin area.

\section{Spatiotemporal dynamics of soil erosion}

According to the statistic results of soil erosion in the lake basin (Table 2), tiny and slight erosion classes were prevalent in the Dianchi Lake basin. Areas of tiny and slight 
erosion exhibited an increasing trend during the 1999-2014 period, increasing from $87.05 \%$ to $91.3 \%$ of the lake basin area. Areas of moderate and severe erosion amounted to a small proportion of the study area, decreasing from $12.95 \%$ to $8.72 \%$ over the 15-year period. Despite the small proportion of moderate and severe erosion areas and the declining trend over time, these two erosion classes contributed a large proportion to total soil erosion, with each contributing more than $42 \%$. Considering the entire Dianchi Lake basin, soil erosion was markedly inhibited over the 15-year period and the erosion area decreased considerably, although prominent erosion persisted in local areas.

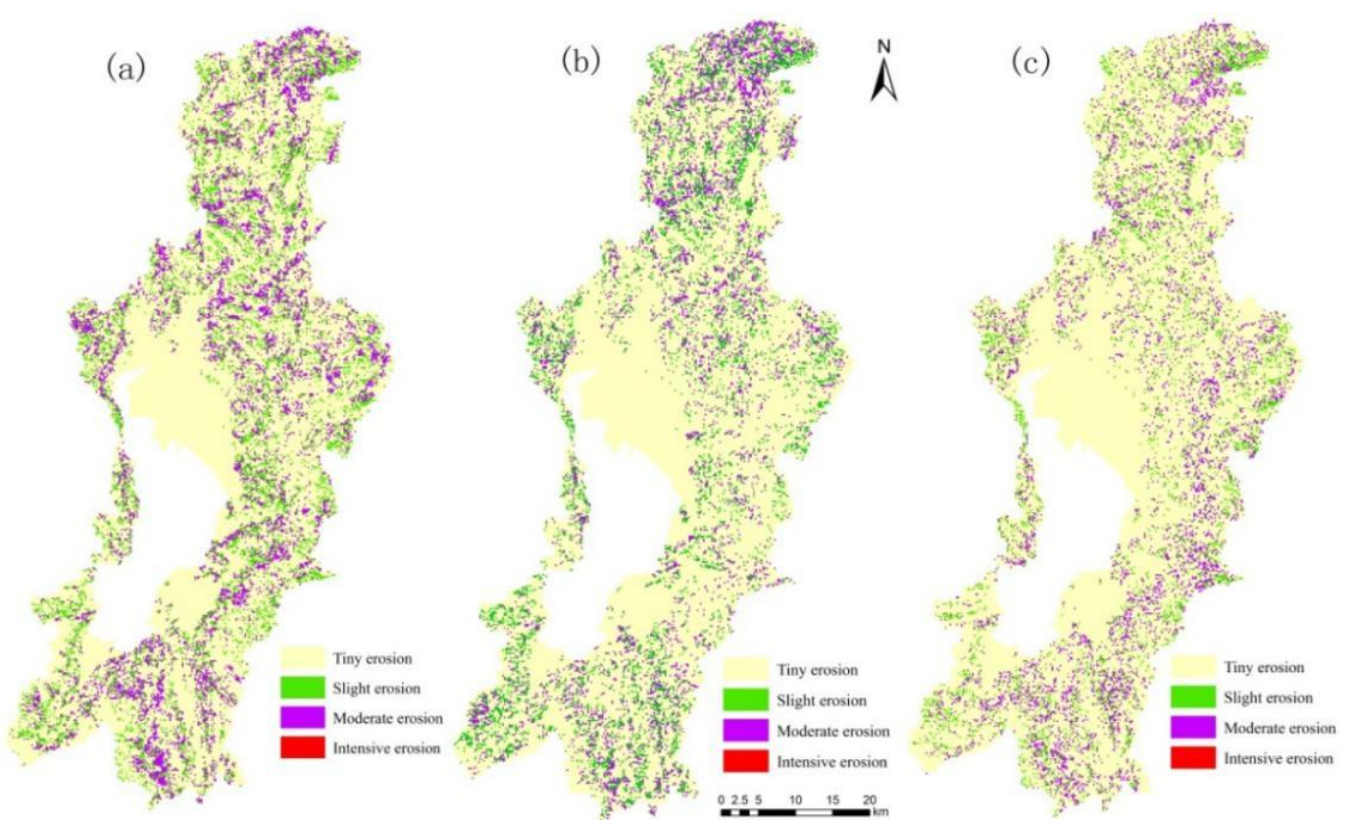

Figure 5. Spatial distribution of soil erosion intensity. (a) 1999, (b) 2005 and (c) 2014

Table 2. Soil erosion intensity statistics in Dianchi Lake basin

\begin{tabular}{|c|c|c|c|c|c|c|c|c|c|c|}
\hline \multirow[b]{2}{*}{$\begin{array}{c}\text { Erosion } \\
\text { intensity }\end{array}$} & \multirow{2}{*}{$\begin{array}{c}\text { Mean } \\
\text { erosion } \\
\text { modulus } \\
\left(\mathbf{t} \cdot \mathbf{k m}^{-2} \cdot \mathbf{a}^{-1}\right)\end{array}$} & \multicolumn{3}{|c|}{1999} & \multicolumn{3}{|c|}{2005} & \multicolumn{3}{|c|}{2014} \\
\hline & & $\begin{array}{c}\text { Erosion } \\
\text { area } \\
\left(\mathbf{k m}^{2}\right)\end{array}$ & \begin{tabular}{|c|} 
Contribution \\
rate \\
$(\%)$
\end{tabular} & $\begin{array}{l}\text { Area } \\
\text { ratio } \\
(\%)\end{array}$ & $\begin{array}{c}\text { Erosion } \\
\text { area } \\
\left(\mathbf{k m}^{2}\right)\end{array}$ & \begin{tabular}{|c|} 
Contribution \\
rate \\
$(\%)$
\end{tabular} & $\begin{array}{l}\text { Area } \\
\text { ratio } \\
(\%)\end{array}$ & $\begin{array}{c}\text { Erosion } \\
\text { area } \\
\left(\mathbf{k m}^{2}\right)\end{array}$ & $\begin{array}{c}\text { Contribution } \\
\text { rate } \\
(\%)\end{array}$ & $\begin{array}{l}\text { Area } \\
\text { ratio } \\
(\%)\end{array}$ \\
\hline $\begin{array}{l}\text { Tiny } \\
\text { erosion }\end{array}$ & $<500$ & 1853.82 & 28.32 & 72.31 & 2056.23 & 35.59 & 80.21 & 2111.21 & 35.00 & 82.37 \\
\hline $\begin{array}{c}\text { Slight } \\
\text { erosion }\end{array}$ & $500 \sim 2500$ & 378.07 & 21.14 & 14.74 & 281.14 & 21.64 & 10.97 & 228.77 & 17.26 & 8.91 \\
\hline $\begin{array}{c}\text { Moderate } \\
\text { erosion }\end{array}$ & $2500 \sim 5000$ & 331.72 & 50.52 & 12.94 & 226.29 & 42.77 & 8.82 & 223.68 & 47.74 & 8.72 \\
\hline $\begin{array}{l}\text { Severe } \\
\text { erosion }\end{array}$ & $>5000$ & 0.05 & 0.02 & 0.01 & 0 & 0 & 0 & 0 & 0 & 0 \\
\hline
\end{tabular}

\section{Discussion}

\section{Soil erosion and slope}

Soil erosion was highly related to the slope. Slope was extracted using the ArcGIS software based on DEM data in this study, divided into six classes according to the "Soil Erosion Classification and Grading Standard (SL90-2007)". Maps of slope class and soil 
loss were subjected to spatial overlap analysis to acquire the relationship between slope and soil loss during the three years 1999, 2005, and 2014 (Table 3). Concerning soil loss, areas with a slope of $8-25^{\circ}$ accounted for more than $52 \%$, the largest proportion, of the total soil loss in the basin. Theoretically, the higher the slope is, the stronger the rainfall erosion kinetic energy will be and the more serious the erosion will be (Liu et al., 1994; Wang, 1998; Berger et al., 2010; Zhao et al., 2015). However, this study found that soil loss presented a prominent decreasing trend when the slope is more than $25^{\circ}$. An overlay analysis of the erosion data of different slopes and high-resolution satellite remote sensing images revealed that areas with a slope greater than $25^{\circ}$ had high vegetation coverage, with slope cropland in a small area and karst rock surface in local areas reducing the occurrence of soil erosion to a large extent. This phenomenon of weakening of erosion intensity with increasing slope due to changes in land cover has been verified by many scholars (Bochet et al., 2009; Zhou et al., 2014).

Table 3. Different slope and soil erosion statistics in Dianchi Lake basin

\begin{tabular}{|c|c|c|c|c|c|c|c|c|c|}
\hline \multirow{2}{*}{$\begin{array}{l}\text { Slope } \\
\left({ }^{\circ}\right)\end{array}$} & \multicolumn{3}{|c|}{1999} & \multicolumn{3}{|c|}{2005} & \multicolumn{3}{|c|}{2014} \\
\hline & $\begin{array}{c}\text { Area } \\
\left(\mathbf{k m}^{2}\right)\end{array}$ & $\begin{array}{l}\text { Soil erosion } \\
\operatorname{loss}\left(10^{4} t \cdot a^{-1}\right)\end{array}$ & $\begin{array}{l}\text { Contribution } \\
\text { rate }(\%)\end{array}$ & $\begin{array}{c}\text { Area } \\
\left(\mathbf{k m}^{2}\right)\end{array}$ & $\begin{array}{c}\text { Soil erosion } \\
\operatorname{loss}\left(10^{4} t \cdot a^{-1}\right)\end{array}$ & \begin{tabular}{|c|}
$\begin{array}{c}\text { Contribution } \\
\text { rate }(\%)\end{array}$ \\
\end{tabular} & $\begin{array}{c}\text { Area } \\
\left(\mathbf{k m}^{2}\right)\end{array}$ & $\begin{array}{c}\text { Soil erosion } \\
\operatorname{loss}_{\left(10^{4} t \cdot a^{-1}\right)}\end{array}$ & $\begin{array}{c}\text { Contribution } \\
\text { rate }(\%)\end{array}$ \\
\hline $0 \sim 5$ & 761.71 & 24.18 & 17.96 & 766.15 & 13.39 & 13.09 & 767.92 & 10.76 & 11.14 \\
\hline $5 \sim 8$ & 217.04 & 15.88 & 11.79 & 213.23 & 9.83 & 9.61 & 214.66 & 9.3 & 9.63 \\
\hline $8 \sim 15$ & 494.15 & 35.03 & 26.01 & 486.7 & 24.63 & 24.08 & 488.23 & 24.44 & 25.31 \\
\hline $15 \sim 25$ & 586.28 & 34.63 & 25.71 & 590.87 & 29.75 & 29.08 & 592.93 & 28.69 & 29.71 \\
\hline $25 \sim 35$ & 354.91 & 18.06 & 13.41 & 345.59 & 17.44 & 17.05 & 347.39 & 16.65 & 17.24 \\
\hline$>35$ & 143.08 & 6.89 & 5.12 & 154.63 & 7.25 & 7.09 & 146.04 & 6.74 & 6.98 \\
\hline
\end{tabular}

\section{Soil erosion and land use type}

Land use is one of the most important factors affecting regional soil erosion. This factor affects soil erosion by altering vegetation cover on the land surface, physical and chemical soil properties, runoff characteristics, and regional climate conditions. Comparative analysis on the relationship between different land use types and the spatial differentiation of soil erosion intensity plays a crucial role in identifying more reasonable land use structures and adopting rational and effective soil and water conservation practices. Herein, the land use types in the Dianchi Lake basin were divided into five classes: cropland, forestland, bare land, construction land, and grassland. The soil erosion area, soil erosion modulus, and annual soil loss in relation to different land use types during the three years of 1999, 2005, and 2014 were acquired using the spatial overlay function of ArcGIS (Table 4). During the 15-year period (1999-2014), cropland area decreased rapidly, whereas construction land and bare land increased sharply; forestland and grassland areas did not change markedly. Total soil loss decreased rapidly by approximately $26.8 \%$, from $134.44 * 104 \mathrm{t} \cdot \mathrm{a}^{-1}$ in 1999 to $98.41 * 104 \mathrm{t} \cdot \mathrm{km}^{-2} \cdot \mathrm{a}^{-1}$ in 2014 , indicating that cropland had a prominent effect on soil erosion in the Dianchi Lake basin. In terms of erosion intensity, the different land use types are ranked as bare land $>$ cropland $>$ forestland $>$ grassland $>$ construction land. Despite the small area of bare land, its mean erosion modulus was relatively high and exhibited rapid growth, increasing 11.9-fold over the 15 years from 1999 to 2014. The erosion contribution from bare land also increased from $0.6 \%$ to $9.1 \%$ over the study period, suggesting that bare land is a priority area that demands attention for the prevention and control of soil erosion in the lake basin area in the future. In particular, 
the cropland area decreased prominently by $60 \%$, from $843.47 \mathrm{~km}^{2}$ in 1999 to $334.91 \mathrm{~km}^{2}$ in 2014 , and total soil erosion loss was reduced by $72 \%$. Forestland area generally followed a decreasing trend but with a small magnitude of decrease, i.e., only a $7.14 \%$ decline over the 15-year period, whereas the soil loss decreased by $12.9 \%$, indicating an improvement in soil erosion mitigation on forestland. Construction land increased rapidly from 1999 to 2014 by three-fold in both area and related soil loss. However, the erosion intensity was substantially low for construction land owing to the special underlying structure, making it a tiny erosion area. Although the erosion area of grassland increased by 1.3-fold, its soil loss increased by only $13 \%$, and the soil loss per unit area exhibited a decreasing trend, suggesting an improvement in soil erosion mitigation for grassland areas.

Table 4. Different land use types and soil erosion statistics in Dianchi Lake basin

\begin{tabular}{|c|c|c|c|c|c|c|c|c|c|}
\hline \multirow[b]{2}{*}{ Land use type } & \multicolumn{3}{|c|}{1999} & \multicolumn{3}{|c|}{2005} & \multicolumn{3}{|c|}{2014} \\
\hline & $\mid \begin{array}{c}\text { Erosion } \\
\text { area } \\
\left(\mathbf{k m}^{2}\right)\end{array}$ & $\begin{array}{c}\text { Mean } \\
\text { erosion } \\
\text { modulus } \\
\left(\mathbf{t} \cdot \mathbf{k m}^{-2} \cdot \mathbf{a}^{-1}\right)\end{array}$ & $\begin{array}{c}\text { Erosion } \\
\text { loss } \\
\left(10^{4} t \cdot a^{-1}\right)\end{array}$ & $\begin{array}{l}\text { Erosion } \\
\text { area } \\
\left(\mathbf{k m}^{2}\right)\end{array}$ & $\begin{array}{c}\text { Mean erosion } \\
\text { modulus } \\
\left(\mathbf{t} \cdot \mathbf{k m}^{-2} \cdot \mathbf{a}^{-1}\right)\end{array}$ & $\begin{array}{c}\text { Erosion } \\
\text { loss } \\
\left(1^{4} t \cdot a^{-1}\right)\end{array}$ & $\begin{array}{c}\text { Erosion } \\
\text { area } \\
\left(\mathbf{k m}^{2}\right)\end{array}$ & $\begin{array}{c}\text { Mean } \\
\text { erosion } \\
\text { modulus } \\
\left(\mathbf{t} \cdot \mathbf{k m}^{-2} \cdot \mathbf{a}^{-1}\right)\end{array}$ & $\begin{array}{c}\text { Erosion } \\
\text { loss } \\
\left(10^{4} t \cdot a^{-1}\right)\end{array}$ \\
\hline Cropland & 844.47 & 743.17 & 62.68 & 655.36 & 584.93 & 38.33 & 334.93 & 519.42 & 17.40 \\
\hline Forestland & 1298.74 & 450.57 & 58.52 & 1263.15 & 394.96 & 49.89 & 1205.35 & 422.66 & 50.97 \\
\hline Bare land & 7.51 & 1070.05 & 0.80 & 19.49 & 951.59 & 1.85 & 89.74 & 706.22 & 6.34 \\
\hline Construction land & 225.64 & 178.87 & 4.03 & 421.55 & 156.61 & 6.60 & 680.9 & 183.26 & 12.48 \\
\hline Grassland & 170.98 & 492.08 & 8.41 & 187.79 & 304.89 & 5.72 & 236.42 & 393.67 & 9.50 \\
\hline
\end{tabular}

In summary, soil erosion under different land use is significantly different, and the contribution rate of different land use to soil erosion varies greatly. Among the land use types, the contribution rate of bare land is the largest (Cerdan et al., 2010; Guo et al., 2013). Labriere et al. (2015) found that soil erosion in the humid tropics is dramatically concentrated in bare land by analyzing more than 3,600 measurement data of soil erosion from 55 references covering 21 countries. Since the building land is isolated from the surface water infiltration into the soil, soil erosion will hardly occur after the construction (Yang, 2019).

\section{Soil erosion and vegetation coverage}

In this study, vegetation coverage is indicated by the normalized difference vegetation index (NDVI). NDVI values were calculated based on the remote sensing image data of the Dianchi Lake basin. The NDVI map was overlaid with the soil erosion map to obtain the relationship between vegetation coverage and soil erosion (Table 5). During the 1999-2014 period, soil erosion correlated with vegetation coverage levels in the lake basin that were between 0 and $45 \%$. The largest erosion contribution occurred when vegetation coverage was between 15 and $30 \%$, and the maximum contribution was $66.35 \%$ in 2014 . Little erosion occurred when vegetation coverage was $45 \%$ or higher, and there was generally no erosion when vegetation coverage was $60 \%$ or higher, indicating that higher vegetation coverage exerted a more prominent inhibiting effect on soil erosion. Thus, vegetation is an important factor in protecting soil against erosion. This result is consistent with the research results of many scholars. Zheng (2006) found that once vegetation restoration, soil erosion was very low in the Loess Plateau, China. And once the vegetation destroyed, soil erosion 
increased markedly. Hou (2014) further revealed that soil erosion was not only affected by vegetation coverage, but also affected by vegetation diversity in the same distribution pattern. The reasons why vegetation plays a significant role in inhibiting soil erosion are as follows: (1) vegetative shoots can satisfactorily reduce the effect of raindrop splash on soil, whereas litter can attenuate the erosion of soil by surface runoff; (2) vegetative roots play a role in retaining the soil, making it difficult to be scoured and transported (Zhang et al., 2014).

Table 5. Statistics of different vegetation coverage and soil erosion in Dianchi Lake basin

\begin{tabular}{|c|c|c|c|c|c|c|c|c|c|}
\hline \multirow[b]{2}{*}{$\begin{array}{c}\text { Vegetation } \\
\text { coverage }(\%)\end{array}$} & \multicolumn{3}{|c|}{1999} & \multicolumn{3}{|c|}{2005} & \multicolumn{3}{|c|}{2014} \\
\hline & $\begin{array}{c}\text { Erosion } \\
\text { area } \\
\left(\mathrm{km}^{2}\right)\end{array}$ & $\begin{array}{c}\text { Mean } \\
\text { erosion } \\
\text { modulus } \\
\left(\mathbf{t} \cdot \mathrm{km}^{-2} \cdot \mathbf{a}^{-1}\right)\end{array}$ & $\begin{array}{l}\text { Contribution } \\
\text { rate }(\%)\end{array}$ & $\begin{array}{c}\text { Erosion } \\
\text { area } \\
\left(\mathrm{km}^{2}\right)\end{array}$ & \begin{tabular}{|c|} 
Mean \\
erosion \\
modulus \\
$\left(\mathrm{t} \cdot \mathrm{km}^{-2} \cdot \mathbf{a}^{-1}\right)$
\end{tabular} & $\begin{array}{c}\text { Contribution } \\
\text { rate }(\%)\end{array}$ & $\begin{array}{c}\text { Erosion } \\
\text { area } \\
\left(\mathbf{k m}^{2}\right)\end{array}$ & $\begin{array}{c}\text { Mean } \\
\text { erosion } \\
\text { modulus } \\
\left(\mathbf{t} \cdot \mathbf{k m}^{-2} \cdot \mathbf{a}^{-1}\right)\end{array}$ & $\begin{array}{c}\text { Contribution } \\
\text { rate }(\%)\end{array}$ \\
\hline $0 \sim 15$ & 869.78 & 524.60 & 33.9 & 876.44 & 258.87 & 22.1 & 619.26 & 179.61 & 11.48 \\
\hline $15 \sim 30$ & 1058.36 & 564.84 & 44.4 & 842.67 & 495.78 & 40.7 & 1401.30 & 458.10 & 66.35 \\
\hline $30 \sim 45$ & 563.93 & 454.63 & 19.0 & 663.76 & 458.94 & 29.7 & 528.29 & 398.16 & 21.74 \\
\hline $45 \sim 60$ & 68.94 & 517.78 & 2.7 & 162.01 & 441.45 & 7.0 & 12.16 & 340.85 & 0.43 \\
\hline $60 \sim 75$ & 0 & 0 & 0 & 16.13 & 290.63 & 0.5 & 0 & 0 & 0 \\
\hline$>75$ & 0 & 0 & 0 & 0 & 0 & 0 & 0 & 0 & 0 \\
\hline
\end{tabular}

\section{Soil erosion and soil erodibility}

The soil erodibility factor $\mathrm{K}$, an intrinsic factor of soil erosion intensity, is the comprehensive expression of soil erosion resistance (Zhang et al., 2011). The relationship between soil erosion modulus and the $\mathrm{K}$ factor in the Dianchi Lake basin was obtained using overlay analysis (Fig. 6).

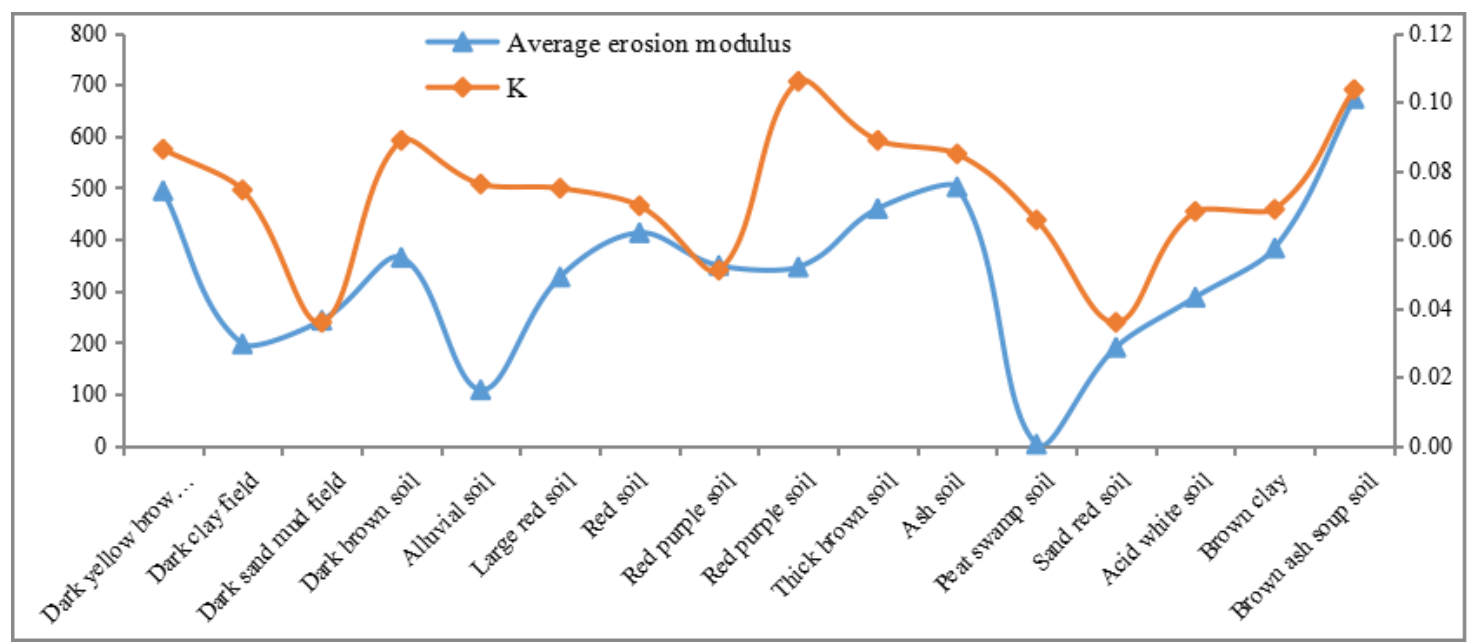

Figure 6. Soil erodibility factor and soil erosion statistics in Dianchi Lake basin

The soil erosion modulus corresponding to various soil types differed. The brownish soup soil had the largest erosion modulus of $672.9 \mathrm{t} \cdot\left(\mathrm{km}^{-2} \cdot \mathrm{a}^{-1}\right)$, which corresponded to a high $\mathrm{K}$ value of $0.10357\left(\mathrm{t} \cdot \mathrm{hm}^{2} \cdot \mathrm{h}\right) /\left(\mathrm{MJ} \cdot \mathrm{mm} \cdot \mathrm{hm}^{2}\right)$, suggesting that this type of soil was prone to erosion. The peat swamp soil had the lowest $K$ value of $0.03583\left(\mathrm{t} \cdot \mathrm{hm}^{2} \cdot \mathrm{h}\right) /\left(\mathrm{MJ} \cdot \mathrm{mm} \cdot \mathrm{hm}^{2}\right)$, whereas the corresponding soil erosion modulus was 
not the lowest. According to the patterns observed in Figure 6, the $\mathrm{K}$ value and soil erosion typically exhibited inconsistent trends in most soil types, except for a few soil types that showed consistent trends, suggesting that the $\mathrm{K}$ factor had a low correlation with soil erosion and hence it is a secondary factor affecting erosion. Theoretically, under the same conditions of rainfall, land use and slope, soils with high erodibility are more susceptible to erosion than those with low erodibility (Panagos et al., 2012; Liu et al., 2020). However, the way of land use indirectly affects the physical and chemical characteristics of soil, which leads to a certain change in soil erodibility (Panagos et al., 2014). Therefore, it is difficult to form a consistent law between soil erosion and $\mathrm{K}$ factor in different regions due to differences in land use patterns (Raquel et al., 2007).

\section{Conclusions}

This study investigated the situation of soil erosion and its relationship with the influencing factors in the Dianchi Lake basin over a 15-year period. The RUSLE model was integrated with remote sensing and GIS, and the remote sensing images of 1999, 2005, and 2014 were used as data sources. The conclusions of the study are as follows:

(1) Analysis of the spatiotemporal dynamics of soil erosion revealed that tiny and slight classes of soil erosion were prevalent in the Dianchi Lake basin during the 15year 1999-2014 period. The tiny erosion area increased over time and amounted to $82.37 \%$ of the lake basin area in 2014, whereas the area and soil loss of light and moderate erosion both decreased over time. As for severe erosion, the erosion contribution was 0 and thus negligible in both 2005 and 2014.

(2) Analysis of the relationship between slope and soil erosion revealed that erosion was primarily concentrated in areas with a slope in the range of $8-25^{\circ}$. The large areas with a slope of $0-5^{\circ}$ were primarily comprised of urban areas, which contributed little to soil erosion and exhibited a decreasing trend in soil erosion over time. For areas with a slope greater than $25^{\circ}$, the soil loss gradually decreased as the slope increased.

(3) Both soil loss and erosion intensity varied significantly between various types of land use. In terms of soil loss, cropland and forestland ranked the highest, which accounted for a decreasing proportion of soil loss over the 15 years, with a maximum of $90 \%$ in 1999 and a minimum of $71 \%$ in 2014. Bare land, construction land, and grassland accounted for a considerably increasing proportion of soil loss, with a total erosion increase of $20 \%$ over the 15 years and the most rapid growth for bare land. As for erosion intensity, the five types of land use were ranked as bare land $>$ cropland $>$ forestland $>$ grassland $>$ construction land, exhibiting a deceasing trend over time.

(4) Considering the relationship between vegetation coverage and soil erosion, erosion was primarily concentrated in areas where the vegetation coverage was less than $45 \%$. In particular, the most intense erosion occurred in areas with vegetation coverage of $15-30 \%$, where the erosion contribution and erosion intensity were at their maximums. Little erosion occurred in areas with vegetation coverage of $45 \%$ or higher, and there was approximately no erosion in areas with vegetation coverage of $60 \%$ or higher. Given the prominent effect of vegetation on mitigating soil erosion, it is recommended that vegetation coverage be increased in the Dianchi Lake basin through various policies, including afforestation and returning cropland to forestland and grassland, to reduce the occurrence of erosion. 
(5) The overlay analysis of the $\mathrm{K}$ factor and soil erosion modulus revealed considerable differences in their change trends, indicating that soil type had a limited effect on erosion.

In summary, the area and intensity of soil erosion exhibited a decreasing trend in the Dianchi Lake basin from 1999 to 2014, indicating a gradual improvement in the situation of soil erosion. There was considerable spatial differentiation in the effects of slope, land use type, vegetation coverage, and soil erodibility on soil erosion. The slope effect on soil erosion was primarily concentrated in the slope range of $8-25^{\circ}$, whereas in areas with a slope greater than $25^{\circ}$ there was a gradually decreasing trend in erosion with increasing slopes. In terms of different types of land use, soil erosion primarily occurred on cropland and forestland. However, as the cropland area decreased rapidly over the 15-year period, its erosion contribution also dropped significantly. Bare land area, however, expanded rapidly and gradually became a major source of erosion because of its high erosion intensity. Areas with vegetation coverage of $15-30 \%$ suffered from the most intense erosion, whereas little erosion occurred in areas with vegetation coverage of $45 \%$ or higher.

Among the above factors, slope, soil erodibility and vegetation coverage were relatively stable, while land use factor was sensitive and had a greater impact on soil erosion. However, land use is significantly affected by human activities. So, further revealing the relationship between human activities factors, such as socio-economic characteristics and regional planning, etc., will help to understand the knowledge of soil erosion mechanism, which will be the focus of the next research.

Acknowledgements. This study was funded by the National Natural Science Foundation of China (No. 41971369, 41561086, 41661082, 41461038).

\section{REFERENCES}

[1] Alexakis, D. D., Hadjimitsis, D. G., Agapiou, A. (2013): Integrated use of remote sensing, GIS and precipitation data for the assessment of soil erosion rate in the catchment area of "Yialias" in Cyprus. - Atmospheric Research 131: 108-124.

[2] Angima, S. D., Stott, D. E., O’Neill, M. K., Ong, C. K., Weesies, G. A. (2003): Soil erosion prediction using RUSLE for central Kenyan highland conditions. - Agriculture, Ecosystems \& Environment 97: 295-308.

[3] Berger, C., Schulze, M., Rieke-Zapp, D., Schlunegger, F. (2010): Rill development and soil erosion: a laboratory study of slope and rainfall intensity. - Earth Surface Processes \& Landforms 35(12): 1456-1467.

[4] Bochet, E., Garcia-Fayos, P., Poesen, J. (2009): Topographic thresholds for plant colonization on semi-arid slopes. - Earth Surface Processes \& Landforms 34(13): 17581771.

[5] Cerdan, O., Govers, G., Le Bissonnais, Y., Van Oost, K., Poesen, J., Saby, N., Gobin, A., Vacca, A., Quinton, J., Auerswald, K., Klik, A., Kwaad, F. J. P. M., Raclot, D., Ionita, I., Rejman, J., Rousseva, S., Muxart, T., Roxo, M. J., Dostal, T. (2010): Rates and spatial variations of soil erosion in Europe: a study based on erosion plot data. - Geomorphology 122(1-2): 167-177.

[6] Chong, C. (2000): Study of applying USLE and geographical information system IDRISI to predict soil erosion in small watershed. - Journal of Soil and Water Conservation 14: $19-24$. 
[7] Fu, B., Yu, L., Lü, Y., He, C., Yuan, Z., Wu, B. (2011): Assessing the soil erosion control service of ecosystems change in the Loess Plateau of China. - Ecological Complexity 8: 284-293.

[8] Gao, Y., Cao, S. (2011): A degradation threshold for irreversible loss of soil productivity: a long-term case study in China. - Journal of Applied Ecology 48: 1145-1154.

[9] Guo, T. L., Wang, Q. J., Bai, W. J. (2013): Effect of land use on scouring flow hydraulics and transport of soil solute in erosion. - Journal of Hydrologic Engineering 23(1A): 215222.

[10] Hartanto, H., Prabhu, R., Widayat, A., Asdak, C. (2003): Factors affecting runoff and soil erosion: plot-level soil loss monitoring for assessing sustainability of forest management. - Forest Ecology \& Management 180: 361-374.

[11] Hou, J., Fu, B., Wang, S., Zhu, H. (2014): Comprehensive analysis of relationship between vegetation attributes and soil erosion on hillslopes in the Loess Plateau of China. - Environmental Earth Sciences 72(5): 1721-1731.

[12] Hu, G., Song, H., Shi, X., Zhang, M., Liu, X., Zhang, X. (2018): Soil Erosion Characteristics Based on RUSLE in the Wohushan Reservoir Watershed. - Scientia Geographica Sinica 38: 610-617.

[13] Jian, H., Wang, H., Fu, B., Zhu, L., Wang, Y., Li, Z. (2016): Effects of plant diversity on soil erosion for different vegetation patterns. - Catena 147: 632-637.

[14] Kinnell, P. (2010): Event soil loss, runoff and the Universal Soil Loss Equation family of models: a review. - Journal of Hydrology 385: 384-397.

[15] Kinnell, P. (2014): Applying the RUSLE and the USLE-M on hillslopes where runoff production during an erosion event is spatially variable. - Journal of Hydrology 519: 3328-3337.

[16] Kinnell, P., Wang, J., Zheng, F. (2018): Comparison of the abilities of WEPP and the USLE-M to predict event soil loss on steep loessal slopes in China. - Catena 171: 99-106.

[17] Labriere, N., Locatelli, B., Laumonier, Y., Freycon, V., Bernoux, M. (2015): Soil erosion in the humid tropics: a systematic quantitative review. - Agriculture Ecosystems \& Environment 203: 127-139.

[18] Lal, R. (2003): Soil erosion and the global carbon budget. - Environment International 29(4): 0-450.

[19] Li, L., Wang, Y., Liu, C. (2014): Effects of land use changes on soil erosion in a fast developing area. - International Journal of Environmental Science \& Technology 11: 1549-1562.

[20] Lin, C., Zhou, S. L., Wu, S. H. (2011): Evolution of soil erosion degree in 30 years in Granite Hills, Southeastern of China - a case study of Changting County, Fujian. Scientia Geographica Sinica 31: 1235-1241.

[21] Liu, B. Y., Nearing, M. A., Risse, L. M. (1994): Slope gradient effects on soil loss for steep slopes. - Transactions of the ASAE 37(6): 1835-1840.

[22] Liu, B. Y., Nearing, M. A., Shi, P. J., Jia, Z. W. (2000): Slope length effects on soil loss for steep slopes. - Soil Science Society of America Journal 64: 1759-1763.

[23] Liu, M., Han, G., Li, X., Zhang, S., Zhou, W., Zhang, Q. (2020): Effects of soil properties on $\mathrm{K}$ factor in the granite and limestone regions of China. - International Journal of Environmental Research and Public Health 17(3): 801.

[24] Manojlovic, S., Antic, M., Sibinovic, M., Dragicevic, S., Novkovic, I. (2017): Soil erosion response to demographic and land use changes in the Nišava River basin, Serbia. - Fresenius Environ Bull 26: 7547-7560.

[25] Mccool, D. K., Brown, L. C., Foster, G. R., Mutchler, C. K., Meyer, L. D. (1987): Revised slope steepness factor for the universal soil loss equation. - Transactions of the Asae 30: 1387-1396.

[26] Miao, C. Y., Yang, L., Chen, X. H., Gao, Y. (2012): The vegetation cover dynamics (1982-2006) in different erosion regions of the Yellow River Basin, China. - Land Degradation \& Development 23: 62-71. 
[27] Mondal, A., Khare, D., Kundu, S., Meena, P. K., Mishra, P. K., Shukla, R. (2015): Impact of climate change on future soil erosion in different slope, land use, and soil-type conditions in a part of the Narmada River basin, India. - Journal of Hydrologic Engineering 20(6): C5014003.

[28] Montgomery, D. R. (2007): Soil erosion and agricultural sustainability. - Proceedings of the National Academy of Sciences 104: 13268-13272.

[29] Nyssen, J., Vandenreyken, H., Poesen, J., Moeyersons, J., Deckers, J., Haile, M. (2005): Rainfall erosivity and variability in the northern Ethiopian highlands. - Journal of Hydrology 311(1-4): 0-187.

[30] Panagos, P., Meusburger, K., Alewell, C., Montanarella, L. (2012): Soil erodibility estimation using LUCAS point survey data of Europe. - Environmental Modelling \& Software 30: 143-145.

[31] Panagos, P., Meusburger, K., Ballabio, C., Borrelli, P., Alewell, C. (2014): Soil erodibility in Europe: a high-resolution dataset based on LUCAS. - Science of the Total Environment 479: 189-200.

[32] Peng, S., Yang, K., Hong, L., Xu, Q., Huang, Y. (2018): Spatio-temporal evolution analysis of soil erosion based on USLE model in Dianchi Basin. - Transactions of the Chinese Society of Agricultural Engineering 34: 138-146 + 305.

[33] Pimentel, D., Harvey, C., Resosudarmo, P., Sinclair, K., Kurz, D., Mcnair, M. (1995): Environmental and economic costs of soil erosion and conservation benefits. - Science 267: 1117-1123.

[34] Raquel, P. R., Marques, M. J., Ramón, B. (2007): Spatial variability of the soil erodibility parameters and their relation with the soil map at subgroup level. - Science of the Total Environment 378(1-2): 166-173.

[35] Renard, K. G., Foster, G. R., Weesies, G. A., McCool, D. K., Yoder, D. C. (1997): Predicting soil erosion by water: a guide to conservation planning with the Revised Universal Soil Loss Equation (RUSLE). - Agriculture Handbook 703: 1-367.

[36] Saygin, S. D., Chi, H. H., Flanagan, D. C., Erpul, G. (2017): Process-based soil erodibility estimation for empirical water erosion models. - Journal of Hydraulic Research 56: 1-15.

[37] Vijith, H., Rekha, V. B., Shiju, C., Rejith, P. G. (2012): An assessment of soil erosion probability and erosion rate in a tropical mountainous watershed using remote sensing and GIS. - Arabian Journal of Geosciences 5: 797-805.

[38] Wang, B., Zheng, F., Roemkens, M. J. M., Darboux, F. (2013): Soil erodibility for water erosion: a perspective and Chinese experiences. - Geomorphology 187: 1-10.

[39] Wang, G. P. (1998): Summary of rill erosion study. - Soil and Water Conservation in China 8: 23-26.

[40] Wang, T. (2018): Quantitative analysis on influencing factors of soil erosion using RUSLE: a case study of the Luohe basin in Northern Shanxi Province. - Environmental Science \& Technology 41: 170-177.

[41] Wen, Y., Liu, X. N., Cheng, J. (2013): Assessment and feature analysis of soil erosion in mountainous area of Guangdong Province based on USLE. - Bulletin of Soil \& Water Conservation 33: 112-118.

[42] Wischmeier, W. H., Johnson, C., Cross, B. (1971): Soil erodibility nomograph for farmland and construction sites. - Journal of Soil and Water Conservation 26: 189-193.

[43] Wischmeier, W. H., Smith, D. D. (1965): Predicting Rainfall Erosion Losses from Cropland East of the Rocky Mountains: Guide for Selection of Practices for Soil and Water Conservation. - In: Agricultural Research Service (ed.) Agr Handbook. No 282. US Dept. Agr., Washington DC.

[44] Xiao, L., Yang, X., Chen, S., Cai, H. (2015): An assessment of erosivity distribution and its influence on the effectiveness of land use conversion for reducing soil erosion in Jiangxi, China. - Catena 125: 50-60. 
[45] Xin, Z., Xu, J., Yu, X. (2009): Temporal and spatial variability of sediment yield on the Loess Plateau in the past 50 years. - Acta Ecologica Sinica 29: 1129-1140.

[46] Yan, Y., Xin, X., Xu, X., Wang, X., Yang, G., Yan, R., Chen, B. (2013): Quantitative effects of wind erosion on the soil texture and soil nutrients under different vegetation coverage in a semiarid steppe of northern China. - Plant Soil 369: 585-598.

[47] Yang, M. (2019): The Impact of Urban building planning on soil and water loss in the peripheral eco-environment. - Ekoloji 28(107): 2521-2531.

[48] Yao, J., Cheng, J., Zhou, Z., Sun, L., Zhang, H. (2018): Effects of herbaceous vegetation coverage and rainfall intensity on splash characteristics in northern China. - Catena 167: 411-421.

[49] Zha, L., Deng, G., Gu, J. (2015): Dynamic changes of soil erosion in the Chaohu Watershed from 1992 to 2013. - Acta Geographica Sinica 70: 1708-1719.

[50] Zhang, J., DeAngelis, D., Zhuang, J. (2011): Spatial Variability of Soil Erodibility (K Factor) at a Catchment Scale in Nanjing, China. - In: DeAngelis, D. L. et al. (eds.) Theory and Practice of Soil Loss Control in Eastern China. Springer, New York.

[51] Zhang, W. B., Fu, J. S. (2003): Rainfall erosivity estimation under different rainfall amount. -- Resources Science 7: 35-41.

[52] Zhang, X., Yu, G. Q., Li, Z. B., Li, P. (2014): Experimental study on slope runoff, erosion and sediment under different vegetation types. - Water Resources Management 28(9): 2415-2433.

[53] Zhao, L., Yuan, G. L., Zhang, Y., Bin, H. E., Liu, Z. H., Wang, Z. Y., Jing, L. I. (2007): The amount of soil erosion in Baoxiang watershed of Dianchi Lake based on GIS and USLE. - Bulletin of Soil \& Water Conservation 3: 42-46.

[54] Zhao, Q., Li, D., Zhuo, M., Guo, T., Liao, Y., Xie, Z. (2015): Effects of rainfall intensity and slope gradient on erosion characteristics of the red soil slope. - Stochastic Environmental Research \& Risk Assessment 29(2): 609-621.

[55] Zheng, F. L. (2006): Effect of vegetation changes on soil erosion on the Loess Plateau. Pedosphere 16(4): 420-427.

[56] Zhou, Q., Yang, S., Cai, M., Lu, Y., Zhao, H., Luo, Y. (2014): Soil erosion and its relationship with topographical factors in a mountainous watershed in the upper Mekong River in Yunnan Province, China. - Fresenius Environmental Bulletin 23(1A): 215-222.

[57] Zhou, Z. C., Shang, Z. P., Zhao, D. (2006): Modeling vegetation coverage and soil erosion in the Loess Plateau Area of China. - Ecological Modelling 198: 263-268.

[58] Zhu, M. (2015): Soil erosion assessment using USLE in the GIS environment: a case study in the Danjiangkou Reservoir Region, China. - Environmental Earth Sciences 73: 7899-7908.

[59] Zokaib, S., Gh., N. (2011): Impacts of land uses on runoff and soil erosion a case study in Hilkot watershed Pakistan. - International Journal of Sediment Research 3: 92-101. 